\title{
Развитие мотивации и смысловой сферы студентов посредством самоактуализации на занятиях по английскому языку
}

\author{
Анна П. Жданько \\ Донской государственный технический университет, г. Ростов-на-Дону, Российская \\ Федерация \\ E-mail: rostov-na-donu.an@yandex.ru
}

\begin{abstract}
Аннотация
Введение. Автором Аоказывается актуальность изучения и развития смысловой сореры студентов с целью повышения мотивации. Новизна исследования закАючается в разработке и апробации Аидактической модели, направленной на повышение мотивации и развитие смысловой сореры студентов посреАством самоактуализации на занятиях по английскому языку, а также в получении новых Аанных о взаимосвязи формирования мотивации и самоактуализации.
\end{abstract}

Методы. В работе использовались опросник Мотивов учебной Аеятельности А. А. Реана, В.А. Якунина и методика самоактуализации мичности Н. Ф. Калины. Аля обработки результатов исследования применялись методы математической статистики (метоА вычисления коэфрфициента ранговой корреляции г-Пирсона, методика определения средней арифрметической величины и среднего квалратического откАонения).

В исследовании приняли участие 78 обучающихся первых и вторых курсов (50 мальчиков, 18 Аевочек) Ростовского государственного университета путей сообщения. Результаты. В результате проведенного исследования изучены показатели самоактуализации, мотивационной сферы студентов и Аоказана эфффективность разработанной нами Аилактической молели, направленной на повышение мотивации, развитие смысловой сореры студентов посреАством самоактуализации с применением механизмов смыслотехнического воздействия на занятиях по английскому языку и преАставляющей собой целостную систему.

ОбсужАение результатов. В заключение Аелается вывоА О том, что выполняя творческие залания, применяя смыслотехнические механизмы воздействия, учитывая культурные и возрастные особенности студентов на занятиях по английскому языку, возможно значительно повысить показатели самоактуализации студентов (креативность, автономность, аутосимпатию, гибкость в общении и т. А.), что в свою очередь приводит к повышению уровня мотивации.

Заключение. САелано заключение о положительной тесной корреляционной связи межАу мотивацией и самоактуализацией студентов (r-Пирсона $=0,98)$. 
ПЕДАГОГИЧЕСКАЯ ПСИХОЛОГИЯ

\title{
КАючевые слова
}

самоактуализация, мотивация, смысловая сорера, смыслотехнические механизмы воздействия, креативность, ценности, культура, возрастные особенности, смыслообразование, самопонимание

\section{Основные положения}

- Аля повышения мотивации стулентов необхолимо увеличить показатели самоактуализации обучающихся (креативность, гибкость в общении, аутосимпатию и т. А.);

- эорорективному увеличению показателей самоактуализации студентов способствует выполнение творческих заланий, применение смыслотехнических механизмов возАействия;

- межАу мотивацией и самоактуализацией существует положительная тесная корреляционная связь.

\section{Для цитирования}

Жданько А.П. Развитие мотивации и смысловой сферы студентов посредством самоактуализации на занятиях по английскому языку // Российский психологический журнал. - 2018. - T. 15, № 1. - С. 77-91. DOI: 10.21702/rpj.2018.1.4

Материалы статьи получены 14.09.2017

UDC 159.923 .38

DOI: 10.21702/rpj.2018.1.4

\section{Development of Students' Motivation and Meaning Sphere by Means of Self-Actualization During English Class}

\section{Anna P. Zhdanko}

Don State Technical University, Rostov-on-Don, Russian Federation

E-mail: rostov-na-donu.an@yandex.ru

\begin{abstract}
Introduction. Studying students' meaning sphere and also its development is important for increasing their motivation. This paper presents new data on the relationship between motivation and self-actualization. The study develops and validates a didactic model for increasing students' motivation and developing their meaning sphere by means of self-actualization during English class.

Methods. The study employed the questionnaire of Motives of Educational Activity by A.A. Rean and V.A. Yakunin; the Personal Self-actualization questionnaire by N.F. Kalina. The analysis of the Pearson correlation coefficient, arithmetic mean, and mean square deviation was conducted for processing of the results. The study
\end{abstract}




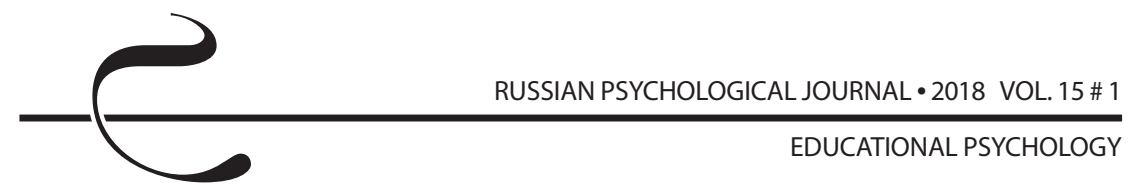

involved 78 first- and second-year students (50 boys and 18 girls) from Rostov State Transport University.

Results. The study revealed the coefficients of self-actualization and motivational sphere. The findings confirmed the validity of the developed didactic model for increasing students' motivation and developing their meaning sphere through self-actualization by means of meaning-making techniques applied during English class. The developed didactic model proved to be an integral system.

Discussion. Performing creative tasks and applying meaning-making techniques during English class, taking into account students' culture- and age-specific features, help to increase their self-actualization (creativity, autonomy, communication flexibility, etc.). These, in turn, increase the level of motivation.

Conclusion. Students' motivation and self-actualization have a strong positive correlation $(r=0,98)$.

\section{Keywords}

self-actualization, motivation, meaning sphere, meaning-making techniques, creativity, values, culture, age-specific features, meaning-making, self-understanding

\section{Highlights}

- Improving the characteristics of students' self-actualization (creativity, communicative flexibility, autosympathy, etc.) helps increase their motivation.

- Creative task performance and meaning-making techniques effectively increase students' self-actualization.

- Motivation and self-actualization have a strong positive correlation.

\section{For citation}

Zhdanko A. P. Development of Students' Motivation and Meaning Sphere by Means of Self-Actualization During English Class. Rossiiskii psikhologicheskii zhurnal - Russian Psychological Journal, 2018, V. 15, no. 1, pp. 77-91 (in Russian). DOI: 10.21702/rpj.2018.1.4

Original manuscript received 14.09.2017

\section{Введение}

Проблема изучения особенностей и механизмов регуляции мотивационной и смысловой сферы молодого поколения приобретает сегодня особую значимость, т. к. в современных условиях интенсивного развития новых технологий и реалий социокультурной жизни общества у молодых людей формируется новая парадигма мышления. Как следствие, возникает объективная необходимость в изучении смысловой сферы и мотивации молодых людей с целью активизации учебной и общественной жизни обучающихся, 
а также формирования успешной личности, умеющей противостоять негативному влиянию извне. Мы солидарны с И.В. Абакумовой, полагающей, что смыслообразовательные регуляции будут возможны при выявлении исходной системы ценностей учащихся [1]. Система ценностей и смысловая сфера человека начинают формироваться в детстве в результате внешней деятельности и в симпраксическом общении. Постепенно экстериоризированная форма деятельности переходит в интериоризированную [2]. В сознании человека начинается многосторонняя жизнь смыслов, эмоций, интересов, потребностей, которые лежат в основе мотивации. Задача педагога - выявить мотивы и особенности смысловой сферы учащихся, скорректировать их и повысить мотивацию, наполнив содержание учебного процесса личностно-значимыми смыслами. Нельзя не согласиться с А.Г. Асмоловым, полагающим, что для повышения мотивации учащихся необходимо «изменить отношение к педагогу», который, как считается, не производит ценностей, т. е. личность учащегося, которую формируют педагоги, не является ценностью [3, с. 314].

Многие зарубежные и отечественные ученые разносторонне изучали и изучают проблему мотивации. Д.А. Леонтьев изучал движущие силы мотивации через призму самоактуализации [4]. А. Маслоу предпринял попытку изучить личность в контексте теории мотивации [5]. В.К. Вилюнас исследовал психологические механизмы мотивации, выделил особый вид мотивации - мотивацию демонстративного поведения [6]. Е.Е. Насиновская рассматривает мотивацию в контексте творчества [7]. В.Т. Фоменко предложил дидактическую модель инициации мотивации обучающихся, заключающуюся в решении задач на смысл [8].

Однако до сих пор не предложена дидактическая модель, направленная на повышение мотивации студентов посредством самоактуализации с применением механизмов смыслотехнического воздействия на занятиях по английскому языку.

Цель проведенного исследования заключалась в изучении смысловой и мотивационной сферы студентов на занятиях по английскому языку.

Для достижения поставленной цели и получения новых результатов, позволяющих судить о динамике развития смысловой и мотивационной сферы обучаемых, была разработана и реализована на практике дидактическая модель, направленная на повышение мотивации студентов посредством самоактуализации с применением механизмов смыслотехнического воздействия.

При реализации дидактической модели на практике мы учитывали не только возрастные и индивидуальные особенности студентов, но и их культурные особенности, т. к. в эксперименте принимали участие представители 


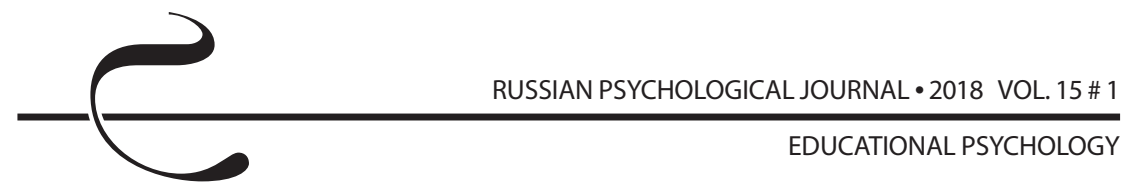

разных культур. Учитывая культурные особенности, необходимо помнить, что родная культура воспринимается единственно правильной. Как справедливо отмечает С.Г. Тер-Минасова, представитель другой культуры, который ведет себя правильно в рамках своей культуры, может восприниматься как «ненормальный» $[9,10]$.

\section{Методы}

Характеристика выборки: общее количество респондентов, принявших участие в исследовании - 78 обучающихся первых и вторых курсов (50 мальчиков, 18 девочек) Ростовского государственного университета путей сообщения.

В исследовании применялись тестовые методы: опросник «Изучение мотивов учебной деятельности» А. А. Реана, В.А. Якунина $[11,12]$ и методика «Самоактуализация личности» Н.Ф. Калины [13]. Также использовались методы математической статистики (метод вычисления коэффициента ранговой корреляции r-Пирсона, методика определения средней арифметической величины и среднего квадратического отклонения).

Изучение смысловой сферы и личности студентов мы начали с изучения мотивации учебной деятельности. Согласно Ф. Уайтли, «мотивация может появляться там, где ее не ожидают, и отсутствовать там, где ожидается» [14, с. 13]. Для изучения мотивов учебной деятельности мы использовали опросник «Изучение мотивов учебной деятельности» А. А. Реана, В.А. Якунина. Студенты оценили 16 предложенных мотивов по 7-балльной шкале. Далее мы подсчитали среднее арифметическое $(\bar{x})$ значение мотива по всей обследуемой выборке и определили среднее квадратическое (б) (стандартное отклонение). На основе полученных данных были выявлены ведущие мотивы учебной деятельности студентов: получить диплом ( $\bar{x}=5,3 ; \sigma=0,94)$, получать стипендию $(\bar{x}=3,6 ; \sigma=0,5)$, добиться одобрения родителей и окружающих $(\bar{x}=3,3 ; \sigma=0,5)$, избежать осуждения и наказания за плохую учебу $(\bar{x}=3$; $\sigma=0,6)$, не отставать от сокурсников $(\bar{x}=2,7 ; \sigma=0,6)$. К сожалению, такие мотивы, как получить интеллектуальное удовлетворение $(\bar{x}=1,1 ; \sigma=0,4)$, стать высококвалифицированным специалистом ( $\bar{x}=1,3 ; \sigma=0,5)$, не вошли в число ведущих.

Далее мы определили индивидуальные особенности студентов, стремление к творчеству, гибкость и контактность в общении, содержательную сторону направленности личности, ее отношение к себе и окружающему миру - с помощью методики «Самоактуализация личности» Н.Ф. Калины. Результаты представлены в таблице 1. 
Таблица 1. Показатели самоактуализации личности студентов, на нача^о эксперимента, в \%

Table 1. Characteristics of students' self-actualization at the beginning of the experiment (percent reporting)

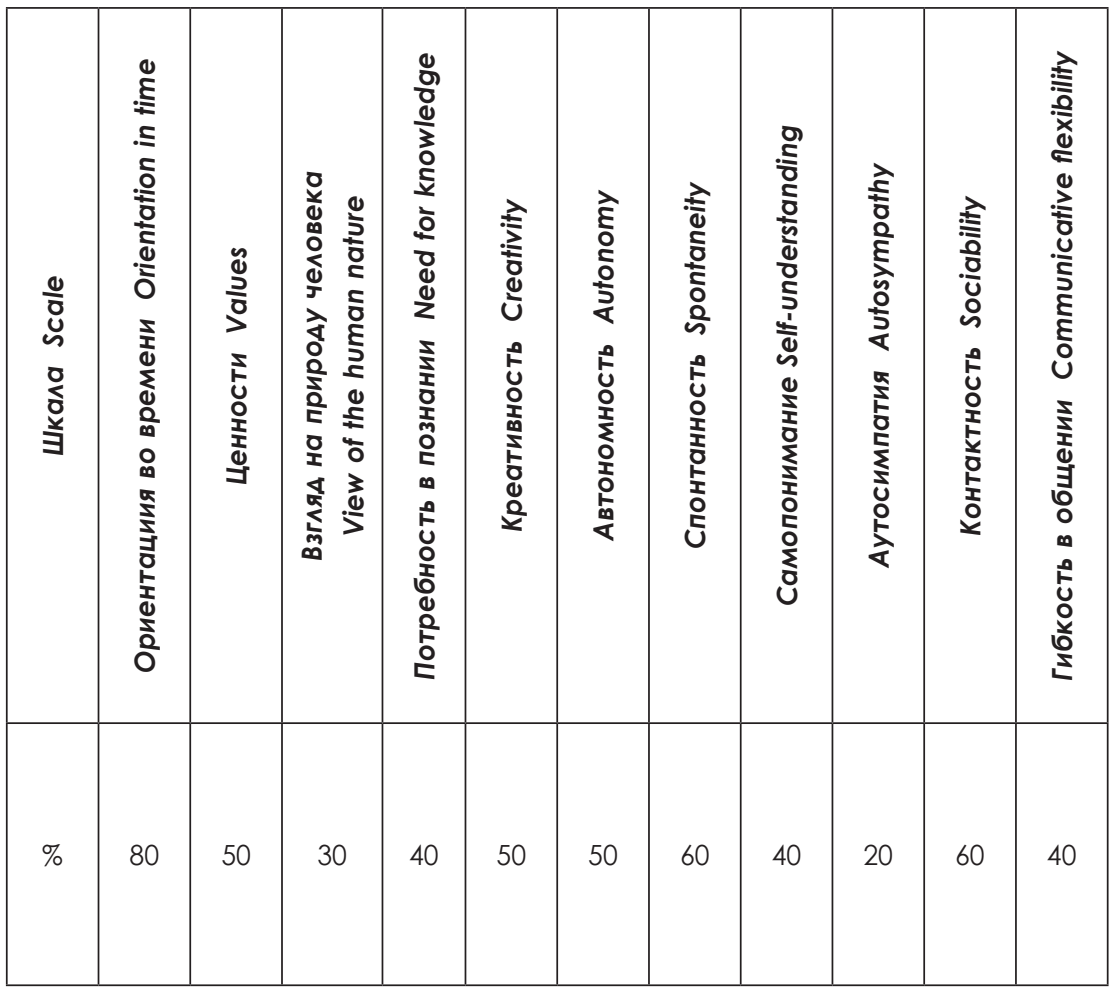

Согласно результатам, большинство студентов (80\%) живут настоящим, т. е. способны наслаждаться настоящим моментом и не пытаются уйти в прошлое. По шкале ценности балл средний (50\%) - это говорит о том, что наряду со стремлением к гармоничным отношениям с людьми присутствует желание манипулирования ими в своих интересах. Вера в могущество человеческих возможностей невысокая (30\%), что свидетельствует о недостаточной честности, непредвзятости в отношениях с людьми. Потребность в познании немного ниже среднего уровня (40\%) - это говорит о том, что интерес к объекту связан с удовлетворением потребностей. Уровень креативности студентов средний (50\%), т. е. присутствует творческое отношение к жизни, что является неотъемлемым атрибутом самоактуализации. Студенты 


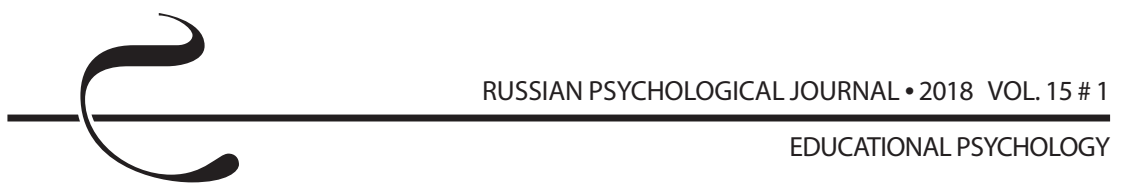

автономны не в полной мере (50\%); под автономностью следует понимать независимость, а не отчужденность. Показатель спонтанности - $60 \%$, что свидетельствует о стремлении к самоактуализации, но недостаточной уверенности в себе. Уровень самопонимания студентов немного ниже среднего (40\%), что говорит о некоторой ориентации на мнение окружающих. Часто проблемы возникают из-за того, что люди «прячут часть своих чувств от самих себя за фальшивой маской принятого обществом поведения» $[15$, с. 579]. Уровень аутосимпатии достаточно низкий (20\%), что свидетельствует о недостаточно позитивной Я-концепции. Уровень контактности немного выше среднего (60\%), что говорит о готовности к общению. Немного не хватает гибкости в общении (40\%), что свидетельствует о присутствии некоторых социальных стереотипов.

\section{Результаты}

Полученные данные позволили с их учетом реализовать дидактическую модель, направленную на повышение мотивации студентов посредством самоактуализации с применением механизмов смыслотехнического воздействия на занятиях по английскому языку. Технологический компонент модели представлен совокупностью следующих составляющих: самоактуализации, использования механизмов смыслотехнического воздействия, учета культурных и возрастных особенностей. Остановимся подробнее на каждом из них.

Нельзя не согласиться с учеными, которые видят синонимом творчества самоактуализацию [16, 17, 18, 19, 20]. Для самоактуализирующейся личности свойственно раскрытие индивидуального потенциала, принятие себя и других такими, какие они есть, креативность, критичность, независимость, преданность своему призванию, альтруизм [21, 22]. Самоактуализация осуществлялась с помощью выполнения творческих заданий (разработки рекламной кампании видеоконтента, деловых игр, интервью с главным героем, драматизации и т. д.). Творчество, эмоциональная вовлеченность опосредуют потребности человека. В таком состоянии легче происходит воздействие, направленное на изменение мотивации. Также в творчестве проявляются потенциальные мотивы, которые не могут быть достигнуты в настоящий момент в силу разных причин (запрет традициями или законом, отсутствие времени, энергии и т. д.), но влияют на жизнь. Мы солидарны с Э. Фроммом, полагающим, что обязанность человека - развить то, что в нем потенциально заложено [23]. Творчество дает возможность педагогу гибко управлять познавательной деятельностью и перейти с эмпирического на концептуальный уровень. Переход с эмпирического уровня содержания образования на концептуальный 
увеличивает шансы интеллектуального развития студентов [24, 25]. В ходе совместной творческой деятельности развиваются самопонимание, аутосимпатия, самоощущение. Мы согласны с Б. Элькониным, полагающим, что самоощущение появляется при взаимодействии с другими людьми, которые осуществляют экранизирующие действия отображения, усиления и возвращения [26]. Творческая деятельность развивает смысловую сферу обучающихся, является поиском смысла. Нельзя не согласиться с В. Франклом, который видел 3 источника смысла жизни: в работе (создании чего-либо значимого), любви (заботе о другом человеке) и в проявлении мужества в тяжелые времена [27].

Для повышения мотивации студентов мы использовали механизмы смыслотехнического воздействия, предложенные Д. А. Леонтьевым. Д.А. Леонтьев предлагает механизм смыслотехнического воздействия, заключающийся в изменении источника смысла, смысловых связей объекта со смыслообразующими источниками, структуры альтернатив [28].

Исследуя смысловую сферу студентов, мы учитывали культурные и возрастные особенности. Повседневный процесс смыслообразования основывается на символической системе той или иной культуры [29]. Юношескому возрасту свойственно стремление к самоактуализации, что способствовало успешному проведению эксперимента.

Экспериментальная проверка нашей дидактической модели позволяет констатировать, что произошли существенные изменения в развитии мотивации, смысловой сферы, самоактуализации студентов. В число ведущих мотивов учебной деятельности вошел мотив обеспечения успешности будущей профессиональной деятельности $(\bar{x}=3 ; \sigma=0,9)$. Хотя мотив получения интеллектуального удовлетворения $(\overline{\mathrm{x}}=1,3 ; \sigma=0,5)$ не стал ведущим, его показатель на конец эксперимента увеличился. В ходе экспериментальной работы подтвердилось предположение отечественных и зарубежных ученых в том, что высокая мотивация компенсирует недостаток способностей, а наличие способностей не может компенсировать отсутствие мотивации [30]. Задача педагога - связать содержимое учебного процесса с индивидуальными способностями студентов и их опытом с целью формирования творческого и критического мышления. Также подтвердилось мнение ученых, полагающих, что мотивированные на успех студенты ставят перед собой достижимые цели и более объективно оценивают свой успех, в отличие от студентов с низкой мотивацией, которые склонны к переоценке или недооценке своего успеха [31]. Нами было замечено, что наиболее сильно мотивация проявлялась при выполнении заданий среднего уровня сложности, а не самых сложных или легких. 
Показатели самоактуализации студентов также увеличились. Результаты представлены в таблице 2.

Таблица 2. Показатели самоактуализации мичности студентов на конец эксперимента, в \%

Table 2. Characteristics of students' self-actualization at the end of the experiment (percent reporting)

\begin{tabular}{|c|c|c|c|c|c|c|c|c|c|c|c|}
\hline $\begin{array}{l}\frac{0}{\delta} \\
\text { U } \\
0 \\
\delta \\
\delta \\
\text { J }\end{array}$ & 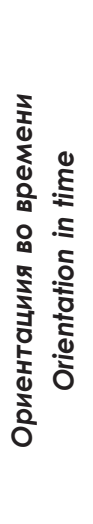 & 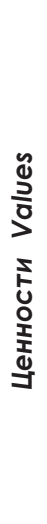 & 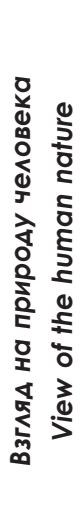 & 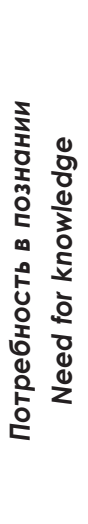 & 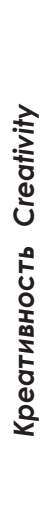 & 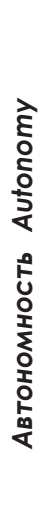 & 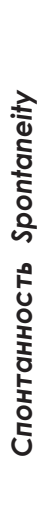 & 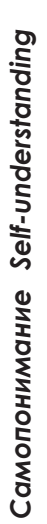 & 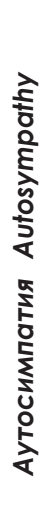 & 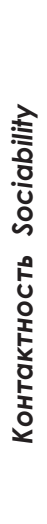 & 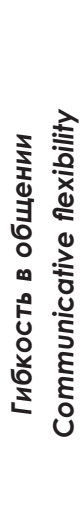 \\
\hline$\%$ & 80 & 60 & 40 & 50 & 70 & 50 & 70 & 50 & 40 & 70 & 50 \\
\hline
\end{tabular}

У студентов появилось больше стремления к гармоничным отношениям с людьми, о чем свидетельствует шкала ценностей (60\%). Студенты стали более открытыми, уверенными в себе, контактными, о чем свидетельствуют шкалы: взгляд на природу человека (40\%), спонтанность (70\%), самопонимание (50\%), аутосимпатия (40\%), контактность (70\%), гибкость в общении (50\%). Отношение к жизни стало более творческим (70\%).

С помощью коэффициента ранговой корреляции Пирсона мы установили положительную корреляционную зависимость между мотивацией и самоактуализацией. Между ними была выявлена тесная корреляционная связь (r-Пирсона = 0,98). Взаимозависимость мотивации и самоактуализации представлена на рисунке 1. 


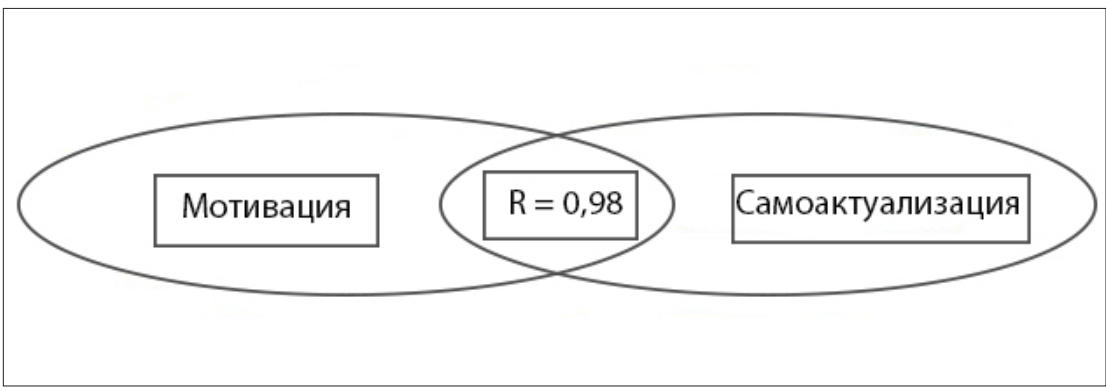

Рисунок 1. Взаимозависимость формирования мотивации и самоактуализации

Figure 1. Interdependence of motivation and self-actualization

\section{Обсуждение результатов}

Результаты проведенного эмпирического исследования позволяют утверждать, что разработанная нами дидактическая модель, направленная на повышение мотивации студентов посредством самоактуализации с применением механизмов смыслотехнического воздействия на занятиях по английскому языку доказала свою эффективность. Дидактическая модель включает в себя следующие технологические компоненты: самоактуализацию студентов посредством выполнения творческих заданий, использование механизмов смыслотехнического воздействия, учет культурных и возрастных особенностей.

В ходе реализации дидактической модели на практике повысился уровень мотивации студентов. В число ведущих мотивов вошел мотив обеспечения успешности будущей профессиональной деятельности ( $\bar{x}=3 ; \sigma=0,9)$. Также повысился уровень самоактуализации студентов. Студенты стали проявлять больше стремления к гармоничным отношениям с людьми, стали более открытыми, уверенными в себе, гибкими в общении, креативными.

Нами была установлена тесная положительная корреляционная связь между мотивацией и самоактуализацией (r-Пирсона =0,98).

\section{Заключение}

Проведенное исследование позволило сделать следующие выводы:

1. В результате проведенного исследования получены данные об уровне показателей самоактуализации (креативности, автономности, самопонимания, аутосимпатии, гибкости в общении и т. д.) и мотивации обучающихся на начало и конец формирующего эксперимента, что позволило проследить динамику их изменения и доказать эффективность разработанной дидактической модели. На конец эксперимента студенты стали в большей степени 
контактными и уверенными в себе, отношения с коллективом стали более гармоничными и гибкими, что выразилось также в повышении показателей самоактуализации. Повысилась мотивация. Мотив обеспечения успешности будущей профессиональной деятельности $(\bar{x}=3 ; \sigma=0,9)$ вошел в число ведущих мотивов учебной деятельности.

2. Показатели самоактуализации значительно увеличились благодаря выполнению студентами творческих заданий, требующих эмоциональной вовлеченности (интервью с главным героем, драматизация, создание видеоконтента и т. д.) и использованию механизмов смыслотехнического воздействия, заключающихся в изменении источника смысла, смысловых связей объекта со смыслообразующими источниками.

3. Корреляционный анализ позволил установить тесную положительную корреляционную связь между мотивацией и самоактуализацией $(r$-Пирсона $=0,98)$ обучающихся на занятиях по английскому языку.

4. Полученные результаты могут использоваться при разработке образовательных смыслодидактических моделей и технологий направленной трансляции смыслов на занятиях по иностранному языку.

\section{Литература}

1. Абакумова И. В., КагермазоваЛ.Ц., Ермаков П. Н. Технологии направленной трансляции смыслов в практике учебного процесса : монография. - М. : КРЕДО, 2016. - 234 С.

2. Леонтьев А. Н. Деятельность. Сознание. Личность. - М. : Смысл, Академия, 2005. - 352 с.

3. Асмолов А. Г. По ту сторону сознания: методологические проблемы неклассической психологии. - М. : Смысл, 2002. - 480 с.

4. Леонтьев Д. А. Современная психология мотивации. - М. : Смысл, 2002. - 343 c.

5. Maslow A. H. Motivation and Personality. - New York : Pearson, 2013. 3rd ed. - $336 \mathrm{p}$.

6. Вилюнас В. К. Психологические механизмы мотивации человека. - М. : Изд-во МГУ, 1990. - 288 с.

7. Насиновская Е. Е. Личность в мире искусства // Журнал практического психолога. Специальный выпуск: Музыкальное движение: психология искусства и художественная практика. - 2016. - № 2. - С. 6-15.

8. Абакумова И. В., Ермаков П. Н., Фоменко В. Т. Новодидактика. Книга 1. Методология и технологии обучения: в поисках развивающего ресурса. - М. : КРЕДО, 2013. - 162 с.

9. Тер-Минасова С. Г. Война и мир языков и культур. - М. : Слово/ Slovo, 2008. - 344 c. 
10.Тер-Минасова С. Г. Язык и межкультурная коммуникация. - М. : Слово/Slovo, 2008. - 264 с.

11. Реан A. A. Психология человека от рождения до смерти. - М. : Изд-во АСТ, 2015. - 665 с.

12. Реан А. А. Психология личности. - СПб. : Питер, 2017. - 288 с.

13. Карелин А. Большая энциклопедия психологических тестов. - М. : Эксмо, 2007. - 416 с.

14. Уайтли Ф. Мотивация / пер. с англ. - М. : Диалектика/Вильямс, 2017. 372 c.

15. Ciccarelli S. K., White N. J. Psychology. - New Jersey : Prentice Hall, 2012. $-610 \mathrm{p}$.

16. Ильин Е. П. Мотивация и мотивы. - СПб. : Питер, 2008. - 512 с.

17. Жданько А. П. Смыслообразующая деятельность учащихся как условие эффективного развития личности и мотивации на занятиях по английскому языку // Российский психологический журнал. - 2015. - Т. 12, № 1. - C. 15-20.

18. Kriz J. Self-Actualization. - Norderstedt : Books on Demand GmbH, 2008. - $216 \mathrm{p}$.

19. Kvalsund R., Baardsen B., Allgood E. Mindfulness Subjectivity through Q Methodology: Training and Practising Mindfulness in an Educational Program as Influential and Transformative // Operant Subjectivity. - 2016. Vol. 38 (2). - P. 33-59. DOI: 10.15133/j.os.2016.006

20. Селезнева Е. В. Грани самоосуществления: от самоотношения к самореализации : монография. - М.-Берлин : Директ-Медиа, 2015. - 404 с.

21. Маслоу А. Новые рубежи человеческой природы / пер. с англ. - М. : Смысл, 2011. - 496 с.

22. Асмолов А. Г. Психология личности: культурно-историческое понимание развития человека. - М. : Смысл, Академия, 2007. - 3-е изд. - 528 с.

23. Фромм Э. Человек для себя. - М. : АСТ, 2016. - 320 с.

24. Абакумова И. В., Ермаков П. Н., Фоменко В. Т. Новодидактика. Книга 2. Образовательные технологии: новые ракурсы. - М. : КРЕДО, 2013. - 122 с.

25. Абакумова И. В., Ермаков П. Н., Фоменко В. Т. Новодидактика. Книга 4. Структурная дидактика как направление современной педагогики. М. : КРЕДО, 2013. - 152 с.

26. Эльконин Б. Д. Самоощущение. Опосредование. Становление действия // Психология телесности между душой и телом / под ред. В. П. Зинченко, Т. С. Леви. - М. : АСТ Москва, 2007. - С. 471-485.

27. FrankI V. E. Man's Search for Meaning. - Boston : Beacon Press, 2014. - 168 p.

28. Леонтьев Д. А. Психология смысла: природа, строение и динамика смысловой реальности. - М. : Смысл, 2007. - 3-е, испр. изд. - 513 с. 
29. Bruner J. Acts of Meaning. - Cambridge, MA : Harvard University Press, 1993. - $181 \mathrm{p}$.

30. Хекхаузен Х. Психология мотивации достижения. - СПб. : Речь, 2001. - 256 c.

31. Heckhausen H. Motivation und Handeln. - Heidelberg : Springer Medizin Verlag, 2010. - 559 s. DOI: 10.1007/978-3-642-12693-2

\section{References}

1. Abakumova I. V., Kagermazova L. Ts., Ermakov P. N. Tekhnologii napravlennoi translyatsii smyslov $v$ praktike uchebnogo protsessa [Technologies of the directed transmission of meanings in the educational process.]. Moscow, CREDO Publ., 2016. 234 p.

2. Leont'ev A. N. Deyatel'nost'. Soznanie. Lichnost' [Activity. Consciousness. Personality]. Moscow, Smysl, Akademiya Publ., 2005. 352 p.

3. Asmolov A. G. Po tu storonu soznaniya: metodologicheskie problemy neklassicheskoi psikhologii [On the other side of consciousness. Methodological problems of non-classical psychology]. Moscow, Smysl Publ., 2002. 480 p.

4. Leont'ev D. A. Sovremennaya psikhologiya motivatsii [Modern psychology of motivation]. Moscow, Smysl Publ., 2002. 343 p.

5. Maslow A. H. Motivation and personality. New York, Pearson Publ., 2013.336 p.

6. Vilyunas V. K. Psikhologicheskie mekhanizmy motivatsii cheloveka [Psychological mechanisms of human motivation]. Moscow, Moscow State University Publ., 1990. 288 p.

7. Nasinovskaya E. E. Personality in the world of art. Zhurnal prakticheskogo psikhologa. Spetsial'nyi vypusk: Muzykal'noe dvizhenie: psikhologiya iskusstva i khudozhestvennaya praktika - Journal of the Practical Psychologist. Special issue: Music movement: Psychology of art and artistic practice, 2016, no. 2, pp. 6-15 (in Russian).

8. Abakumova I. V., Ermakov P. N., Fomenko V. T. Novodidaktika. Kniga 1. Metodologiya i tekhnologii obucheniya: v poiskakh razvivayushchego resursa [New didactics. Book 1. Methodology and technology of training: Searching a developing resource]. Moscow, CREDO Publ., 2013. 162 p.

9. Ter-Minasova S. G. Voina i mir yazykov i kul'tur [War and the world of languages and cultures]. Moscow, Slovo Publ., 2008. 344 p.

10. Ter-Minasova S. G. Yazyk i mezhkul'turnaya kommunikatsiya [Language and intercultural communication]. Moscow, Slovo Publ., 2008. 264 p.

11. Rean A. A. Psikhologiya cheloveka ot rozhdeniya do smerti [Human psychology from birth to death]. Moscow, AST Publ., 2015. 665 p.

12. Rean A. A. Psikhologiya lichnosti [Psychology of personality]. St. Petersburg, Piter Publ., 2017. 288 p. 
13. Karelin A. Bol'shaya entsiklopediya psikhologicheskikh testov [Great encyclopedia of psychological tests]. Moscow, Eksmo Publ., 2007. 416 p.

14. Whiteley Ph. Motivation (Russ. ed.: Uaitli F. Motivatsiya. Moscow, Dialektika/ Vil'yams Publ., 2017. 372 p.).

15. Ciccarelli S. K., White N. J. Psychology. New Jersey, Prentice Hall Publ., 2012. $610 \mathrm{p}$.

16. Il'in E. P. Motivatsiya i motivy [Motivation and motives]. St. Petersburg, Piter Publ., 2008. 512 p.

17. Zhdanko A. P. Meaning-making activity among students as a condition for effective development of personality and motivation during English class. Rossiiskii psikhologicheskii zhurnal - Russian Psychological Journal, 2015, V. 12, no. 1, pp. 15-20 (in Russian).

18. Kriz J. Self-actualization. Norderstedt: Books on Demand GmbH, 2008. 216 p.

19. Kvalsund R., Baardsen B., Allgood E. mindfulness subjectivity through Q methodology:Training and practising mindfulness in an educational program as influential and transformative. Operant Subjectivity, 2016, V. 38 (2), pp. 33-59. DOI: 10.15133 / j.os.2016.006

20. Selezneva E. V. Grani samoosushchestvleniya: ot samootnosheniya k samorealizatsii [Self-realization facets: From self-relation to self-realization]. Moscow-Berlin, Direct Media Publ., 2015. 404 p.

21. Maslow A. The farther reaches of human nature. Harmondsworth, Penguin, 1971 (Russ. ed.: Maslou A. Novye rubezhi chelovecheskoi prirody. Moscow, Smysl Publ., 2011.496 p.).

22. Asmolov A. G. Psikhologiya lichnosti: kul'turno-istoricheskoe ponimanie razvitiya cheloveka [Personality psychology: Cultural and historical understanding of human development]. Moscow, Smysl, Academy Publ., 2007. 528 p.

23. Fromm E. Man for himself (Russ. ed.: Fromm E. Chelovek dlya sebya. Moscow, AST Publ., 2016. 320 p.).

24. Abakumova I. V., Ermakov P. N., Fomenko V. T. Novodidaktika. Kniga 2. Obrazovatel'nye tekhnologii: novye rakursy [New didactics. Book 2. Educational technology: new perspective]. Moscow, CREDO Publ., 2013. 122 p.

25. Abakumova I. V., Ermakov P. N., Fomenko V.T. Novodidaktika. Kniga 4. Strukturnaya didaktika kak napravlenie sovremennoi pedagogiki [New didactics. Book 4. Structural didactics as a direction of modern pedagogics]. Moscow, CREDO Publ., 2013. 152 p.

26. El'konin B. D. Self-sentiment. Mediation. Formation of action. In: Zinchenko V. P., Levi T. S. (eds.) Psikhologiya telesnosti mezhdu dushoi i telom [Psychology of corporeality between body and soul]. Moscow, AST Moskva Publ., 2007, pp. 471-485.

27. Frankl V. E. Man's search for meaning. Boston, Beacon Press, 2014. 168 p. 
28. Leont'ev D. A. Psikhologiya smysla: priroda, stroenie i dinamika smyslovoi real'nosti [Psychology of meaning: Nature, structure, and dynamics of meaning reality]. Moscow, Smysl Publ., 2007. 513 p.

29. Bruner J. Acts of meaning. Cambridge, MA, Harvard University Press, 1993. $181 \mathrm{p}$.

30. Heckhausen H. The anatomy of achievement motivation. N. Y., 1967 (Russ. ed.: Khekkhauzen Kh. Psikhologiya motivatsii dostizheniya. St. Petersburg, Rech' Publ., 2001. 256 p.).

31. Heckhausen H. Motivation und Handeln. Heidelberg, Springer Medizin Verlag, 2010. 559 p. DOI: 10.1007/978-3-642-12693-2 